\title{
Chronic hyperinsulinemia reduces insulin sensitivity and metabolic functions of brown adipocyte
}

\author{
Sujith Rajan1,2,*, Kripa Shankar1,*, Muheeb Beg1, Salil Varshney', Abhishek Gupta', \\ Ankita Srivastava1,2, Durgesh Kumar,,2, Raj K Mishra³, Zakir Hussain4, \\ Jiaur R Gayen ${ }^{4}$ and Anil N Gaikwad1,2 \\ 1Division of Pharmacology, CSIR-Central Drug Research Institute, Lucknow, Uttar Pradesh, India \\ ${ }^{2}$ Academy of Scientific and Innovative Research, CSIR-Central Drug Research Institute, Lucknow, Uttar Pradesh, India \\ ${ }^{3}$ SIPS Superspeciality Hospital, Lucknow, Uttar Pradesh, India \\ ${ }^{4}$ Division of Pharmacokinetics, CSIR-Central Drug Research Institute, Lucknow, Uttar Pradesh, India \\ *(S Rajan and K Shankar contributed equally to this work)
}

Correspondence should be addressed to A N Gaikwad Email

anil_gaikwad@cdri.res.in

\begin{abstract}
The growing pandemics of diabetes have become a real threat to world economy. Hyperinsulinemia and insulin resistance are closely associated with the pathophysiology of type 2 diabetes. In pretext of brown adipocytes being considered as the therapeutic strategy for the treatment of obesity and insulin resistance, we have tried to understand the effect of hyperinsulinemia on brown adipocyte function. We here with for the first time report that hyperinsulinemia-induced insulin resistance in brown adipocyte is also accompanied with reduced insulin sensitivity and brown adipocyte characteristics. $\mathrm{Cl}$ treatment decreased expression of brown adipocyte-specific markers (such as PRDM16, PGC1 $\alpha$, and UCP1) and mitochondrial content as well as activity. $\mathrm{Cl}$-treated brown adipocytes showed drastic decrease in oxygen consumption rate (OCR) and spare respiratory capacity. Morphological study indicates increased accumulation of lipid droplets in Cl-treated brown adipocytes. We have further validated these findings in vivo in C57BL/6 mice implanted with mini-osmotic insulin pump for 8 weeks. $\mathrm{Cl}$ treatment in mice leads to increased body weight gain, fat mass and impaired glucose intolerance with reduced energy expenditure and insulin sensitivity. Cl-treated mice showed decreased BAT characteristics and function. We also observed increased inflammation and ER stress markers in BAT of Cl-treated animals. The above results conclude that hyperinsulinemia has deleterious effect on brown adipocyte function, making it susceptible to insulin resistance. Thus, the above findings have greater implication in designing approaches for the treatment of insulin resistance and diabetes via recruitment of brown adipocytes.
\end{abstract}

\author{
Key Words \\ - human mesenchymal \\ stem cells \\ - differentiation \\ - brown adipocytes \\ - insulin \\ - insulin resistance
}




\section{Introduction}

Obesity has become a world-impending problem consuming \$2 trillion of the world economy (McKinsey 2014 report). According to WHO, nearly one third of the adult world population comes in overweight and obese category (WHO report 2015). Obesity is defined as excess accumulation of body fat or adipose tissue and is considered to be the antecedent of metabolic disorders such as insulin resistance (IR), type 2 diabetes, hypertension, dyslipidemia, cardiovascular diseases, etc. (Ye 2013). Numerous studies, on both animals and humans, have inferred negative correlation between body weight and insulin sensitivity (Cinti 2012). Weight gain in the body is largely due to accumulation of white adipose tissue (WAT); thus, insulin resistance can directly be correlated with WAT (Wajchenberg 2000). In last couple of decades, scientists have explored the composition of different fat pads and their physiological functions. There are mainly two functionally divergent fat tissues present in adults, white adipose tissue (WAT) and brown adipose tissue (BAT). WAT is abundant in body, whereas the latter is barely present in adults. Although the association of WAT and insulin resistance is known since three decades, recently scientist have correlated the decrease in BAT with obesity and insulin resistance (Vijgen et al. 2011). Lowell and coworkers showed that brown adipose tissueablated mice exhibit increased obesity, diabetes, and hyperlipidemia (Lowell et al. 1993, Hamann et al. 1996). 18 FDG-PET/CT studies have corroborated decreased BAT content in person with increased body mass index (BMI) (Cypess et al. 2009, Ouellet et al. 2011). Above studies indicate that a balance between WAT and BAT is necessary to maintain energy homeostasis and healthy body composition. Recent evidences have associated BAT with non-shivering thermogenesis, lipolysis, fatty acid oxidation, insulin sensitivity, and improved serum lipid profile (Zhang et al. 2014). Study conducted by Gray et al showed that hyperinsulinemia precedes insulin resistance in mice lacking pancreatic leptin signaling (Gray et al. 2010). This was further confirmed in obese human by Alemzadeh and coworkers in which authors have shown beneficial effect of diazoxide on obese hyperinsulinemic adults (Shanik et al. 2008). Clinical observations have shown higher basal insulin level in obese persons, which indicates inefficiency of adipose tissue to respond to insulin (Erdmann et al. 2008). The effect of hyperinsulinemia on WAT has been studied extensively, but not much has been interrogated in BAT. The effect of prolonged hyperinsulinemia on functioning of BAT in obese person remains to be explored. The beneficial effects of BAT have motivated scientific community and it is now being stipulated as a promising therapeutic strategy to cure obesity and insulin resistance (Liu et al. 2013). Before soliciting further, whether this strategy will work in a hyperinsulinemic obese environment needs to be established.

In this study for the first time, we have shown the effects of hyperinsulinemia on differentiated and characterized brown adipocytes. Basal chronic hyperinsulinemia (500 pM insulin exposure for $72 \mathrm{~h}$ ) causes insulin resistance in both white and brown adipocytes differentiated from hMSC. Surprisingly, we found decreased expression of brown adipocyte markers such as UCP1, PGC1 $\alpha$, and less active mitochondria on chronic treatment with insulin. Brown adipocytes on CI treatment show decreased oxygen consumption and respiratory capacity. We have also validated these findings in chronic exogenous hyperinsulinemia-induced insulin resistance in mice model. Our results further strengthens the existing notion that hyperinsulinemia acts as a precursor for the development of insulin resistance in both white and brown adipocytes.

\section{Research design and methods}

\section{Isolation and characterization of hMSC from liposuction sample}

Liposuction samples were obtained from patient undergoing fat reduction surgery with their informed consent. Approval for isolation of adipose-derived stem cells was obtained from Institutional Committee on Stem Cell Research (ICSCR) of Dr Ram ManoharLohia Institute of Medical Science (RML-IMS), Lucknow (IEC No: 20/14). Stromal vascular fraction (SVF) was isolated from liposuction samples using collagenase digestion as described in Zuk et al. (2002) with few modifications. Briefly, lipoaspirate was washed thoroughly in phosphate buffer saline (PBS) containing 1\% penicillin/streptomycin solution (Gibco) and digested with $1 \%$ collagenase type-Ia (Sigma Chemical) for $30 \mathrm{~min}$ at $37^{\circ} \mathrm{C}$. Dulbecco's modified Eagle's medium (DMEM) (Gibco) containing 20\% FBS (Gibco) was added to nullify the action of collagenase and centrifuged at $400 \mathrm{~g}$ for $10 \mathrm{~min}$. The pellet obtained was suspended in DMEM and filtered through $70 \mu \mathrm{M}$ cell strainer. Isolated cells were characterized using human MSC analysis kit (Catalogue: 562245) obtained from BD stem flow. The characterization was done based on surface markers CD73+, CD90+, and CD105+ using flow cytometry.

Published by Bioscientifica Ltd. 


\section{hMSC culture and differentiation into white and brown adipocytes}

hMSC was cultured in high-glucose DMEM supplemented with 10\% fetal bovine serum (Gibco) and antibiotics. hMSC was differentiated using a differentiation cocktail containing $500 \mu \mathrm{M}$ IBMX, $5 \mu \mathrm{g} / \mathrm{mL}$ insulin, $1 \mu \mathrm{M}$ dexamethasone, and $200 \mu \mathrm{M}$ indomethacin (all purchased form Sigma Chemicals). Treatment of differential cocktail was given as shown in Fig. 1(C). Fully mature white adipocytes (WA) after 12 days of differentiation were treated as mentioned in the figure legends and in the Results section.

Human mesenchymal stem cell are known to differentiate into white and brown adipocytes; recently, Elabd and coworkers showed that human adipose-derived multipotent stem cell can also be differentiated into functionally active brown adipocytes (Elabd et al. 2009). We followed a similar protocol with few modifications. We used induction media containing $0.5 \mu \mathrm{M}$ rosiglitazone and $2 \mathrm{nM} \mathrm{T}_{3}$ (tri-iodothyronine) to differentiate hMSC into brown adipocytes (Fig. 2A). A schematic diagram of white and brown adipocyte differentiation protocol is shown in Figs. 1C and 2A.

\section{Insulin resistance development}

To mimic basal hyperinsulinemia, differentiated adipocytes were incubated with $500 \mathrm{pM}$ insulin (Sigma, cat no I5500) in $10 \mathrm{mM}$ glucose media supplemented with $10 \% \mathrm{FBS}$ for $72 \mathrm{~h}$. Medium was changed every $24 \mathrm{~h}$ to replenish the insulin level. After $72 \mathrm{~h}$, cells were washed extensively using KRH buffer $(121 \mathrm{mM} \mathrm{NaCl}, 4.9 \mathrm{mM} \mathrm{KCl}$, $1.2 \mathrm{mM} \mathrm{MgSO}_{4}$, and $0.33 \mathrm{mM} \mathrm{CaCl}_{2}$ ) supplemented with $5 \mathrm{mM}$ glucose and $0.5 \%$ BSA (step-down media) before acute insulin pulsing.

\section{Oil red $O$ staining}

Performed as described elsewhere (Beg et al. 2015).

\section{[3H] 2-deoxyglucose uptake}

Determination of 2-DOG uptake in differentiated adipocyte was performed as described previously (Sashidhara et al. 2014). Glucose uptake was measured in triplicate well (three sets of experiments) and normalized with total protein expressed as fold induction with respect to unstimulated cells. Radioactivity retained by the cell lysate was measured by liquid scintillation counter (Beckman Coulter LS 6500; Beckman Coulter Inc, Brea, CA, USA).

\section{Real-time PCR}

Total RNA was isolated from cells using TRIZOL reagent (Invitrogen). First-strand cDNA synthesis was performed using high-capacity cDNA reverse transcription kit (Applied Biosystems) and subsequently used for quantitative real-time PCR analysis on Light Cycler 480 (Roche Diagnostics) using SYBR Green master mix (Roche diagnostics). Statistical analysis of the quantitative realtime PCR was done using ( $\left.2^{-\Delta \Delta C t}\right)$ method, which calculates the relative changes in gene expression. Relative change in gene expression was normalized with endogenous reference gene (18S rRNA). The primers used to check the expression of different genes are presented in Table 1.

\section{JC-1 and tetramethylrhodamine, ethyl ester (TMRE) staining}

JC-1 (M34152) and TMRE (T669) dye were procured from Invitrogen Life Technologies and experiments were performed as per the manufacturers' protocol, briefly fully differentiated adipocytes were washed with PBS and incubated with TMRE $(500 \mathrm{~nm})$ and JC1 $(2 \mu \mathrm{M})$ for $30 \mathrm{~min}$. The cells were washed with PBS and images were taken using high-content screening platform Cellomics (Array Scan VTI).

\section{Mitochondrial respiration study}

To study mitochondrial respiration activity, hMSC were seeded in eight-well Flux analyzer (Seahorse Biosciences, North Billerica, MA, USA) cell plate at a density of 10,000 cells/well. Cells were allowed to grow till confluence and were differentiated into brown and white adipocytes as mentioned above. Oxygen consumption rate (OCR) of white and brown adipocytes was determined using XFp Extracellular Flux analyzer (Seahorse Bioscience). We used $1 \mu \mathrm{M}$ oligomycin, $1 \mu \mathrm{M}$ FCCP, and $0.5 \mu \mathrm{M}$ rotenone/ antimycin A mixture as per manufacturer's protocol. Readings were normalized with total protein concentration.

\section{Western immunoblotting}

Western blotting was performed as described previously (Beg et al. 2015). Densitometric quantification of protein bands was performed using National Institute of Health (NIH) Image J software.

Published by Bioscientifica Ltd 
A

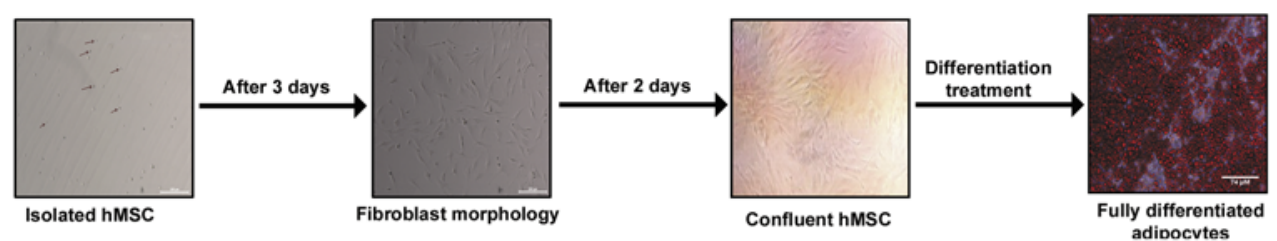

B
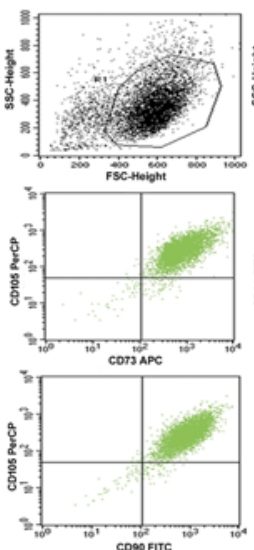
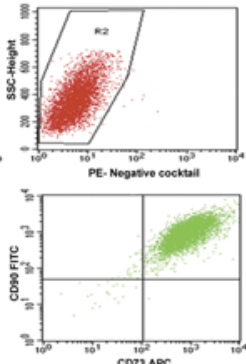

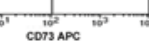

C
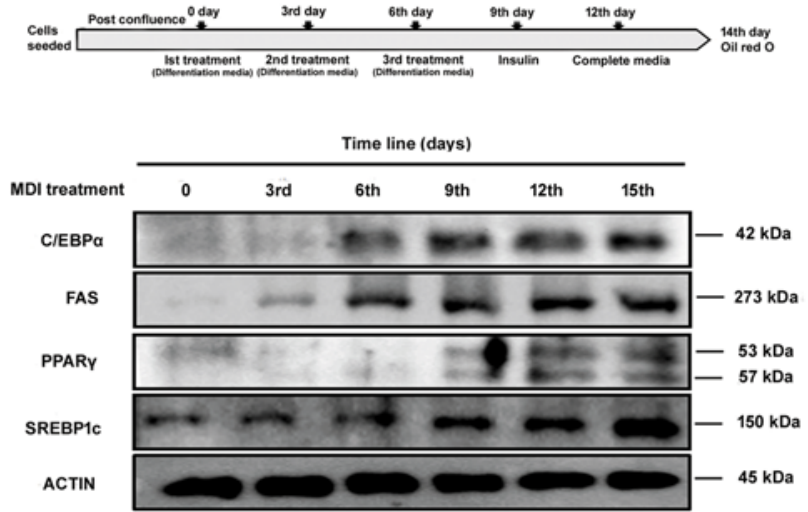

D
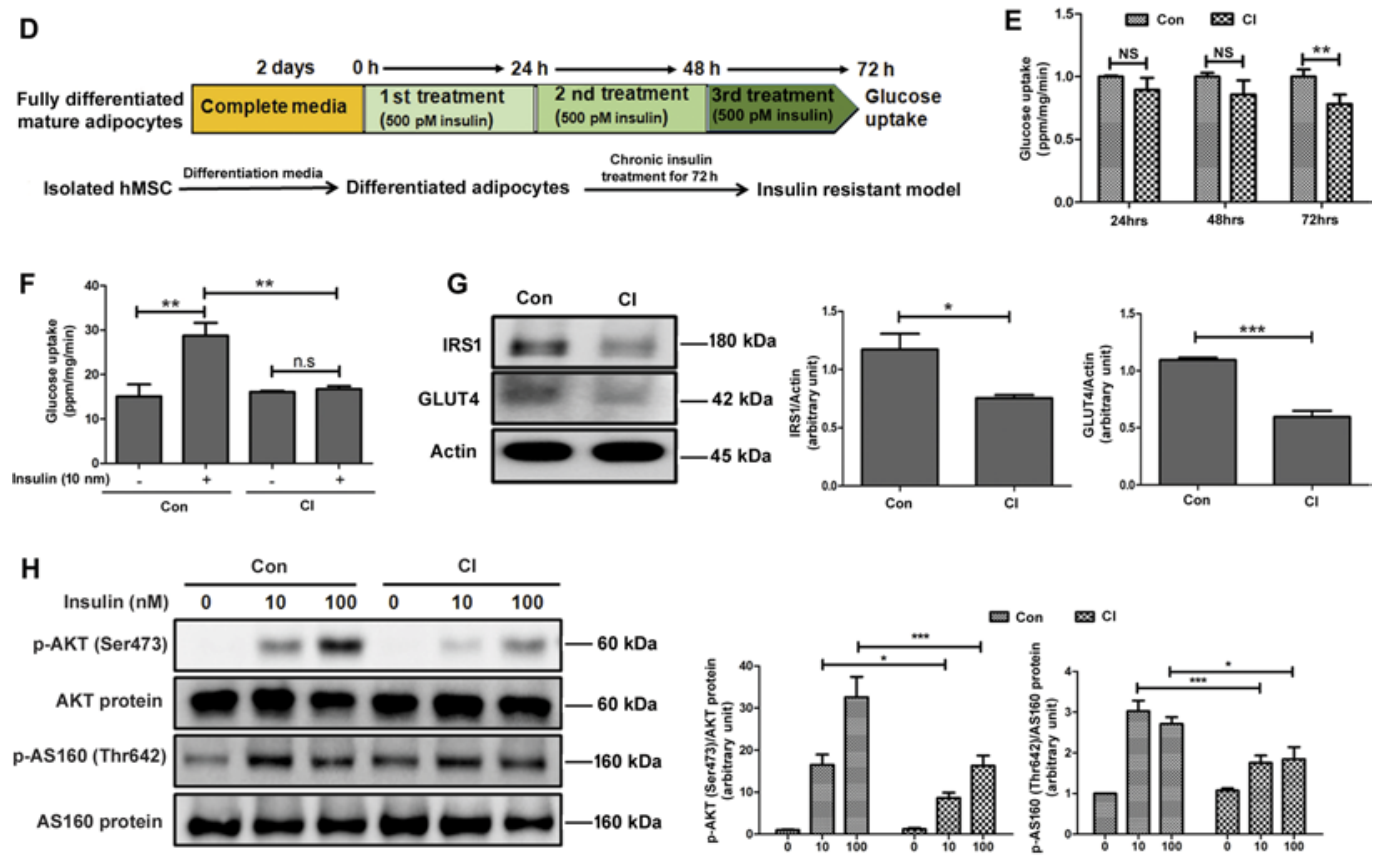

Figure 1

Insulin resistance model development in adipocyte differentiated from hMSC. hMSC after 1 day of isolation (image a), hMSC with fibroblast morphology (image b), confluent hMSC (image c), and hMSC differentiated into fully mature adipocyte stained with oil red $\mathrm{O}$ (image d), all the images were taken at 10x magnification with Leica DFC450 C (A). hMSC isolated from six different liposuction samples were pooled together for flow cytometry analysis in BD FACS Caliber. Negative cocktail contained CD34, CD45, CD11b, and CD19. 20,000 counts were taken in each reading (B). Schematic diagram of differentiation treatment and western blot analysis of adipocyte-specific transcription factors at different time intervals during the period of 15 days of differentiation treatment, $n=3$ (C). Schematic diagram of chronic insulin treatment in adipocyte (D). Glucose uptake was measured at 24-h intervals during the period of chronic insulin treatment. Control and Cl-treated adipocytes were stimulated with $10 \mathrm{nM}$ insulin for $20 \mathrm{~min}$. Data are represented as fold difference, $n=3$, error bars represent s.D., $* * * P<0.001$ as compared by Student's $t$-test (E). Glucose uptake of control and 72 -h Cl-treated adipocytes with and without $10 \mathrm{nM}$ insulin stimulation for $20 \mathrm{~min}, n=3$ error bars represent s.D., $* * P<0.005$ as compared by Student's $t$-test (F). All glucose uptake readings were normalized with respective protein concentration. Western blot analysis of IRS1 and GLUT4 in control and $\mathrm{Cl}$-treated adipocytes normalized with actin. Densitometry of respective blots are shown in left panel, $n=3$, error bars indicate s.D., * $P<0.05$ at tested by Student's $t$-test (G). Western blot analysis of p-AKT (Ser 473) and PAS160 (Thr 642) in control and Cl-treated adipocytes upon varying concentration of insulin stimulation $(20 \mathrm{~min})$. Densitometry of blots normalized with total AKT and AS160 protein is shown adjacent to the blots, $n=3$, error bars represent s.D., ${ }^{*} P<0.05$, $* * * P<0.001$ as compared by Student's $t$-test $(\mathrm{H})$. 

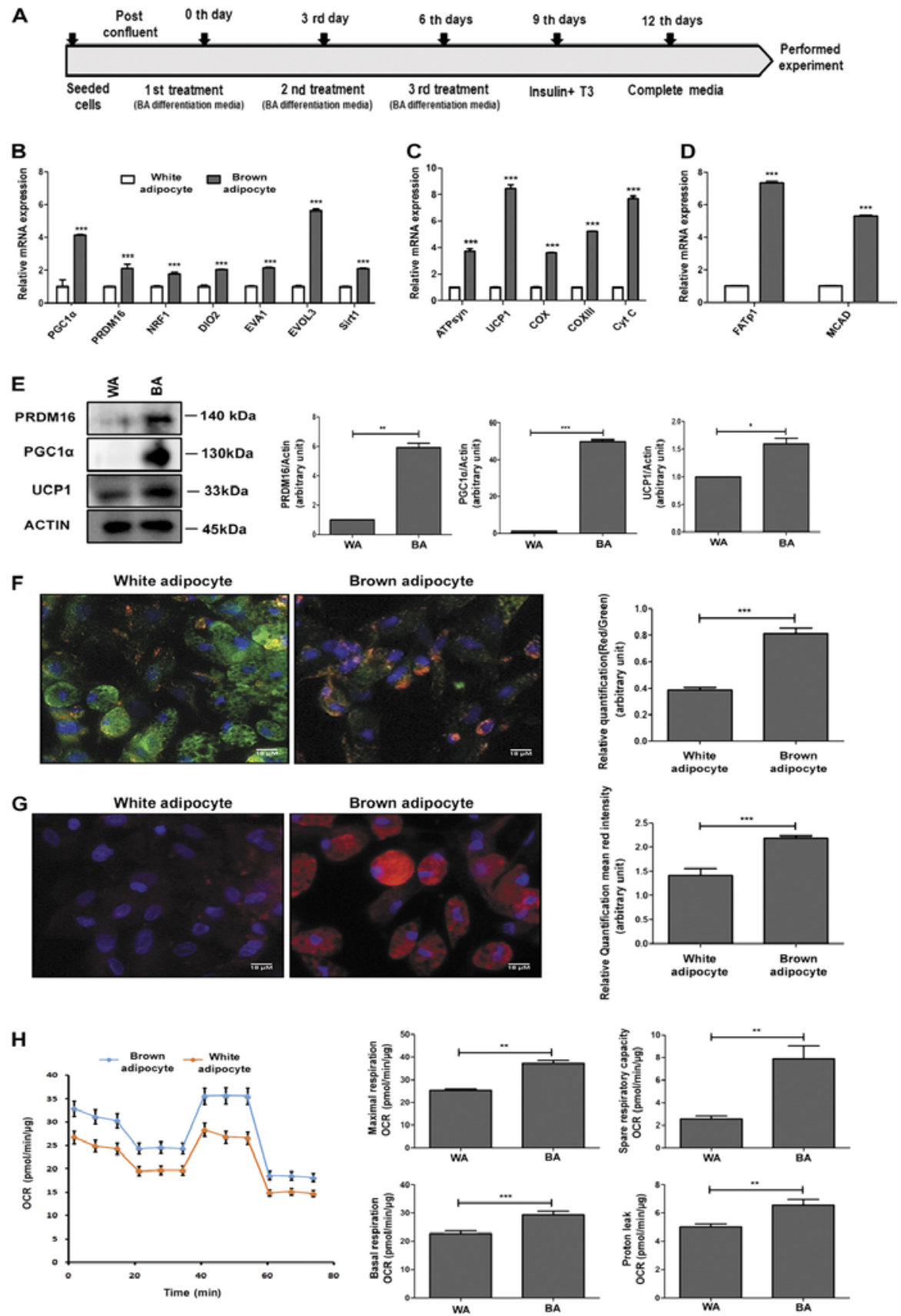

Figure 2

Differentiation of hMSC into brown adipocytes. Schematic diagram of brown adipocyte differentiation protocol (A). Brown adipocyte differentiated using the above mentioned protocol was subjected to RNA isolation and real-time PCR. Expression profile of brown adipocyte-specific marker genes compared with white adipocytes, $n=3$, error bars represent S.D., $* * * P<0.001$ as tested two-way ANOVA and Bonferroni's post-test analysis (B). Real-time PCR analysis of genes related to mitochondrial biogenesis and fatty acid oxidation, $n=3$, error bars represent s.D., $* * * P<0.001$ as tested two-way ANOVA and Bonferroni's post-test analysis ( $C$ and $D$ ). Western blot analysis of PRDM16, PGC1 $\alpha$, and UCP1 in white and brown adipocytes. Densitometry of representative blots normalized with actin, $n=3$, error bar indicates S.D., $* * * P<0.001, * * P<0.01$, and $* P<0.05$ as tested by Student's $t$-test (E). White and brown adipocytes were grown in 96 -well eppendroff clear bottom imaging plate and stained with JC-1 dye. Cells were excited with 405 or $488 \mathrm{nM}$ and image was taken at 20x magnification using Cellomics (high-content screening platform). Images were analyzed using image J software. The red fluorescence shows high-membrane potential mitochondria (J aggregates). The green florescence shows low-membrane potential mitochondria (L monomers). The graph on the right-hand side is the relative quantification of red to green ratio normalized with nuclear stain DAPI. $n=3$, the error bars denote s.D., $* * * P<0.001$ (F). Brown and white adipocytes were stained with TMRE dye. The cells were excited at $405 \mathrm{nM}$. Images were taken at 20x magnification and analyzed similar to the above experiment. The graph besides the image shows the relative quantification of mean red intensity normalized with DAPI. $n=3$, error bars represent S.D., $* * * P<0.001$ as tested by Student's $t$-test (G). The oxygen consumption rates (OCR) of brown and white adipocytes at basal level and in the presence of ATP synthase inhibitor ( $1 \mu \mathrm{M}$ oligomycin), proton uncoupler $(1 \mu \mathrm{M}$ FCCP), and electron transport chain inhibitors $(0.5 \mu \mathrm{M}$ rotenone/antimycin mix) was measured with Seahorse Bioscience XFp Extracellular Flux analyzer. $n=3$, error bars represent s.D., $* * P<0.005$, $* * * P<0.001$ as tested by Student's $t$-test $(\mathrm{H})$. 


\section{Animal care and treatment}

The study was conducted in 6 to 8 -week-old C57BL/6 male mice at the animal facility of CSIR-Central Drug Research Institute. All experimental procedures were approved by the institutional animal ethics committee and were conducted in accordance with the guidelines of the Committee for the purpose of Control and Supervision of Experiments on Animals (CPCSEAs), India. The mouse housing environment includes a temperature of $23 \pm 2^{\circ} \mathrm{C}$, humidity $50-60 \%$, light 300 Lux at floor level with regular $12 \mathrm{~h}$ light cycle.
Totally, 16 male mice were housed (eight mice/cage) and given water and normal chow diet ad libitum.

\section{Implantation of mini-osmotic pump}

Alzet osmotic pumps filled with saline or insulin (glargine) were primed for at least $24 \mathrm{~h}$ in sterile saline in a $37^{\circ} \mathrm{C}$ water bath according to the manufacturer's instructions. These saline- or insulin-filled pumps were implanted subcutaneously for 4 weeks and re-implanted the fresh saline- or insulin glargine-filled pump for

Table 1 Primer sequences used for quantitative RT-PCR.

\begin{tabular}{lc} 
& Homo sapeins \\
\hline Gene $\quad$ Primer sequence
\end{tabular}

PGC1d Reverse

PGC1d Forward

PRDM16 Reverse

PRDM16 Forward

TTATTGGGAAATGCCTCCTG

GGGTCATTTGGTGACTCTGG

CGGATGTTCCCCAACAAGTA

NRF1 Reverse

NRF1 Forward

ATP5G1-001 ATP synthase

Reverse

ATP5G1-001 ATP synthase

Forward

CIDEA Reverse

CIDEA Forward

DIO2 Reverse

DIO2 Forward

ELOVL3 Reverse

ELOVL3 Forward

UCP1 Reverse

UCP1 Forward

MPZL2 Reverse

MPZL2 Forward

SIRT1 Reverse

SIRT1 Forward

Cytochrome oxidase Reverse

Cytochrome oxidase Forward

Cytochrome oxidase III

Reverse

Cytochrome oxidase III

Forward

Cytochrome C Reverse

Cytochrome C Forward

SLC27A1 Reverse

SLC27A1 Forward

RhsR-MCAD Reverse

RhsF-MCAD Forward

CPT1 beta Reverse

CPT1 beta Forward
CATTTGTACTCGCGCTCCT

CCATCTGGTGGCCTGAAG GTAGTGCCTGGGTCCATGA AGGGCTAAAGCTGGGAGACT

TTAGACCCCTGGTACAACAGC

GTCATGGGAAGCGAGCAC TGGGTTTATTGCAGGAGATGA TACCCGTCTTAGGCAGCAAC AAACATCTGCTGGGTCTTCG AACCTGCAAGGGCCTCTC GCCCCCAGGATACTGAAGAT GGAAGCAAGATTTTAGCTGGTCT GTGGGTTGCCCAATGAATAC TCTGCCTGTGCACTGATGAT GAGCTCTTTCGGCCCATC TTCAGACCATTTTTGAACATCACT GAACAGCTATATTTCAAACCCTTTTT TTCTGTTGCGGGAAGCTC GAAGAACGTAGCCGCTTGG GCAGGATTTTTCTGAGCCTTT

\section{GGGATTTAGCGGGGTGAT}

ATAGCGTCCACAGGCATAGC ACAGTCCGAAGATGATGGTAAAG GTGTCGAGGTGCCAGGAA TCCTTCTCCAAGACCTGAGC GGAGCCATTGATGTGTGCT CTGCTTTGGTCTTTATACCAGCTA CCCTATGCTCTACAGCTTCCA GGGCGCACAGACTCTAGGTA

\begin{tabular}{ll}
\hline \multicolumn{1}{c}{ Mus musculus } \\
\cline { 1 - 2 } Gene & Primer sequence \\
\hline Elov13 Reverse & GGCACCATCTTTGGCATACT \\
ElovI3 Forward & AGTGTTCCGTTGTTGTGTG \\
Atp5g1-001 Atp synthase & CATTTGTGTGCCCAGTTTCA \\
Reverse & \\
Atp5g1-001 Atp synthase & GGGACAGGGATTTGATTCAC \\
Forward & \\
Cox IV Reverse & CTCCCTGCCTCCCTCACT \\
Cox IV Forward & AGCATGGACCATTGGATACG \\
Cox III Reverse & TAGCCTCGTACCAACACATGA
\end{tabular}

Cox III Forward

AGTGGTGAAATTCCTGTTGGA

Fatp1 Reverse

Fatp1 Forward

Cdh15 Reverse

Cdh15 Forward

Ucp1 Reverse

Ucp1 Forward

Pgc1a Reverse

Pgc1a Forward

Dio2 Reverse

Dio2 Forward

Nrf1 Reverse

Nrf1 Forward

Cpt1a Reverse

Cpt1a Forward

Prdm16 Reverse

Prdm16 Forward

GACAAGCTGGATCAGGCAAG

GAGGCCACAGAGGCTGTTC CGCCGGAACACTTACTATGC GCGTCAGTGGCTAGCTGATT TAAGCCGGCTGAGATCTTGT GGCCTCTACGACTCAGTCCA GAACCCTTGGGGTCATTTG CCCATACACAACCGCAGTC TGAGAAGTCTGGTACATCAGCAA TGGCATGCCCTGTAGGTT GAACAACACAGATTCCATGCTC GCCTCCCGATAGTTTGAGAAA TGGCATAGCTGTCAATAGATGC GACGAATCGGAACAGGGATA CACCTTCCGCTTTTCTACCC

\section{CCTAAGGTGTGCCCAGCA}

Tnf $\alpha$ Forward

Tnf $\alpha$ Reverse Mapk8 Forward Mapk8 Reverse IL1 beta Forward IL1beta Reverse Ccl2 Forward Ccl2 Reverse IL6 Forward IL6 Reverse F4/80 Forward F4/80 Reverse
CATCTTCTCAAAATTCGACTCACAA TGGGAGTAGACAAGGTACAACCC AGAAACTGTTCCCCGATGTG ACAAATCTCTTGCCTGACTGG AGTTGACGGACCCCAAAAG AGCTGGATGCTCTCATCAGG CTTCTGGGCCTGCTGTTCA CCAGCCTACTCATTGGGATCA GAGGATACCACTCCCAACAGACC AAGTGCATCATCGTTGTTCATACA TGTCCTCCTTGCCTGGAC GAGACTTCTGAGCTGACACTGC 
additional 4 weeks. So the total duration of the pump implanted with saline or insulin (glargine) was 8 weeks. For insertion of pumps, mice were anesthetized briefly with ketamine $(80 \mathrm{mg} / \mathrm{kg})$ and xylazine $(10 \mathrm{mg} / \mathrm{kg})$. The insertion site was shaved and disinfected with povidoneiodine and 70\% alcohol. Post-surgery and implantation of mini-osmotic pumps, wounds were closed with sterile sutures and monitored throughout experiment. None of the mice exhibited signs of infection at the insertion site. About $10 \%$ glucose solution was provided in drinking water for the first 7 days to prevent hypoglycemia. These mice were kept on the normal chow diet.

\section{Serum and organ collection}

After 8 weeks, mice were fasted for $6 \mathrm{~h}$ and killed using anesthetic ether. Blood was collected from orbital sinus. Serum was isolated by centrifugation at $12,000 \boldsymbol{g}$ for $15 \mathrm{~min}$ at $4^{\circ} \mathrm{C}$. Epididymal white adipose tissue (eWAT) and interscapular brown adipose tissue (iBAT) were excised from the 8-week continuous saline and CI-treated animals after acute pulsing with insulin $(0.75 \mathrm{U} / \mathrm{kg})$.

\section{Serum insulin and lipid profile}

Serum levels of total cholesterol, triglyceride, LDLcholesterol, and HDL-cholesterol were analyzed using kits from Randox Laboratory Ltd (Mumbai, India). Serum insulin concentrations were determined by enzymatic immunoassay (SPI-BIO, Bertin Pharam, Montigny le-Bretonneux, France).

\section{Body weight}

Body weight of the mice was recorded weekly.

\section{Intraperitoneal glucose tolerance test}

Intraperitoneal glucose tolerance test (IPGTT) was performed as described previously. Briefly, mice were fasted for $6 \mathrm{~h}$. Basal fasting glucose was measured with the help of Accu-Check active glucometer. For glucose tolerance test, glucose $(2 \mathrm{~g} / \mathrm{kg})$ was administered intraperitoneally, and blood glucose was measured at 15, 30, 60, 90, and $120 \mathrm{~min}$ from tail tip.

\section{Insulin tolerance test}

Insulin tolerance test was performed in 5 -h fasted mice. Regular insulin $(0.75 \mathrm{U} / \mathrm{kg}$, Sigma Aldrich) was injected intraperitoneally, and glucose was measured at $0,15,30$, 60 , and $90 \mathrm{~min}$ from tail tip.

\section{Energy expenditure analysis by oxymax/comprehensive lab animal monitoring system (CLAMS)}

Oxymax/CLAMS (Columbus Instruments, Columbus, $\mathrm{OH}, \mathrm{USA}$ ) were used to quantitate food intake, locomotor activity, oxygen consumption $\left(\mathrm{VO}_{2}\right)$, carbon dioxide production $\left(\mathrm{VCO}_{2}\right)$, metabolic rate, and heat production. Mice treated with saline or chronic insulin were individually housed in chambers maintained at $24 \pm 1^{\circ} \mathrm{C}$ and given free access to chow diet and water. All the measurements were taken every $15 \mathrm{~min}$ for 3 days after the mice were acclimatized for 1 day. Basal metabolic rate (BMR) was determined by averaging lowest plateau region of oxygen consumption curve corresponding to resting periods. All data collected were averaged from 3 days of monitoring.

\section{Body composition analysis}

Body composition was measured after 8 weeks of saline or chronic insulin treatment using ${ }^{1} \mathrm{H}$ NMR spectroscopy (EchoMRI 3-in-1, Echo Medical Systems Ltd, Houston, TX, USA)

\section{Statistical analysis}

Results are expressed as mean \pm S.D. for at least three to five separate determinations for each experiment. Densitometry of western blot data expressed as mean \pm s.D. of three independent experiments. Statistical significance was determined by Student's $t$-test and one-way ANOVA for real-time results (GraphPad Prism version 3). $P$ values $<0.05$ were considered significant.

\section{Results}

\section{Insulin resistance model development in adipocyte differentiated from hMSC}

International stem cell association describes hMSC based on surface markers CD73, CD90, and CD105 (HermidaGomez et al. 2011). hMSC isolated from six different liposuction samples were pooled together for flow cytometry analysis and further experiments. More than 98\% of cells were positive for CD105, CD73, and CD90 surface markers. Cocktail containing CD34, CD11b, CD19, and CD45 was used as negative markers (Fig. 1B).

Published by Bioscientifica Ltd. 
Cells showed fibroblast morphology and differentiated into adipocyte on treatment with differentiation cocktail. On treatment with differentiation cocktail (MDI), most of the cells acquired lipid droplets, which were stained with oil red O (Fig. 1A). hMSCs on treatment with induction media show increased expression of adipocyte-specific markers such as FAS, PPAR $\gamma, \mathrm{C} / \mathrm{EBP} \alpha$, and SREBP1c (Fig. 1C). Fully differentiated white adipocytes were treated with $500 \mathrm{pM}$ insulin as shown in experimental design (Fig. 1D). Timedependent exposure of $500 \mathrm{pM}$ insulin on differentiated adipocytes showed decreased insulin-stimulated (10nM) glucose uptake at 24 and $48 \mathrm{~h}$, but significant decrease was obtained only at $72 \mathrm{~h}$ (Fig. 1E). We confirmed above result at 72-h time point with/without insulin stimulation in control and CI-treated adipocytes (Fig. 1F). From here onward, 72 -h treatment of $500 \mathrm{pM}$ is mentioned as CI. We further confirmed insulin resistance at protein level. CI treatment significantly decreased IRS1 and GLUT4 expression compared with control adipocytes (Fig. 2G). One of the major functions of insulin is to translocate cytosolic GLUT4 to membrane that is mediated in part by activation of AKT and downstream substrate AS160 protein. We found that CI treatment significantly decreased insulin-stimulated phosphorylation of AKT and As160 compared with control adipocytes (Fig. 2H). The above results confirm that adipocytes differentiated from hMSC on treatment with pathophysiological level of insulin $(500 \mathrm{pM})$ for $72 \mathrm{~h}(\mathrm{CI})$ show characteristics of insulin resistance.

\section{Differentiation of hMSC into brown adipocytes}

hMSCs were differentiated into brown adipocyte as shown in Fig. 1A. Adipocyte differentiated using the above protocol showed increased expression of brown

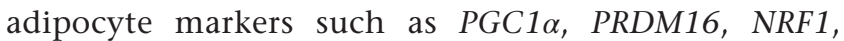
DIO2, EVA1, EVOL3, and SIRT1 compared with white adipocytes (Fig. 2B). Expression of mitochondrial and fatty acid oxidation-related genes such as ATP synthase, UCP1, COX, COX III, CYT C, FATp1, and MCAD were also increased in brown adipocytes (Fig. 2C and D). We confirmed increase in the expression of UCP1, PGC $1 \alpha$, and PRDM16 protein levels in brown adipocytes (Fig. 2E). Morphologically brown adipocytes are known to have high number of mitochondria compared with white adipocytes. JC-1 and TMRE staining confirmed significantly high number of functionally active mitochondria in brown adipocytes differentiated from hMSC compared with white adipocytes (Fig. 2F and G). Oxygen consumption rate (OCR) of brown adipocytes was considerably higher compared with white adipocytes, indicating that the latter is metabolically more active compared with white adipocytes. Basal and maximal respirations of brown adipocytes were also significantly higher compared with white adipocytes, indicating increased functionally active population of mitochondria. Spare respiratory capacity and proton leak were found to be significantly high in brown adipocytes compared with white adipocytes (Fig. 2H). The spare respiratory capacity indicates the amount of extra ATP that can be produced during energy stress. It also demonstrates how well the cell is equipped to moderate energy deficiency. The brown adipocytes differentiated from hMSC thus indicate superior mitochondrial function than white adipocytes.

\section{Chronic insulin treatment decreases expression of brown adipocyte-specific markers and leads to insulin resistance in brown adipocytes}

The effect of hyperinsulinemia on white adipocytes has been extensively studied and documented in the literature. To probe the effect of hyperinsulinemia on brown adipocytes, we subjected brown adipocytes to similar CI treatment. We found that brown adipocytes become resistant to insulin-stimulated glucose uptake similar to white adipocytes on CI treatment (Fig. 3A). To further validate insulin resistance in brown adipocytes, we studied insulin signaling level alteration in CI treated white and brown adipocytes. CI treated brown adipocytes showed decreased insulin stimulated phosphorylation of AKT (Ser473) and AS160 (Thr642) similar to CI treated white adipocytes. We also found decrease expression of Glut4 in CI treated brown adipocytes compared to control brown adipocytes (Fig. 3B). The above results prompted us to study the effect of hyperinsulinemia on functioning of brown adipocytes. Our result indicates that CI treatment decreases the expression of brown adipocyte-specific markers and transcription factors PRDM16, PGC1 $\alpha$, DIO2, SIRT1, etc. (Fig. 3C). We also found decreased expression of mitochondria and fatty acid oxidationrelated genes such as UCP1, COX, COX III, CYT C, FATP1, and MCAD in CI-treated brown adipocytes (Fig. 3D and E). The above results indicate decrease in metabolic activity and uncoupling property of brown adipocyte on CI treatment. We have further validated CI-induced decrease in brown adipocyte markers such as PGC1 $\alpha$, UCP1, PRDM16, and SIRT1 at protein level (Fig. 3F). We found increased expression of ER

Published by Bioscientifica Ltd. 
A

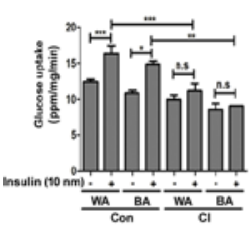

B

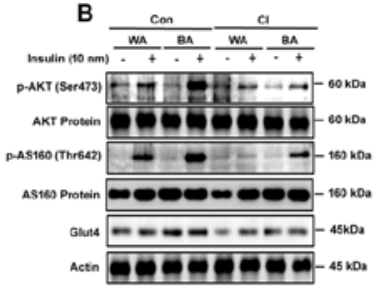

D

C

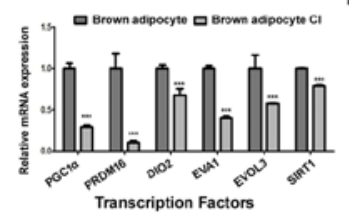

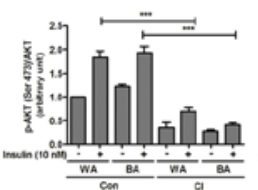
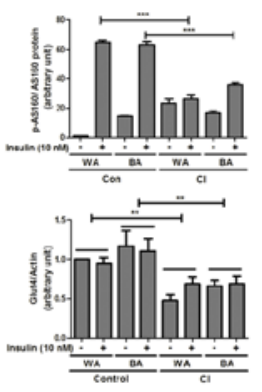

E

E
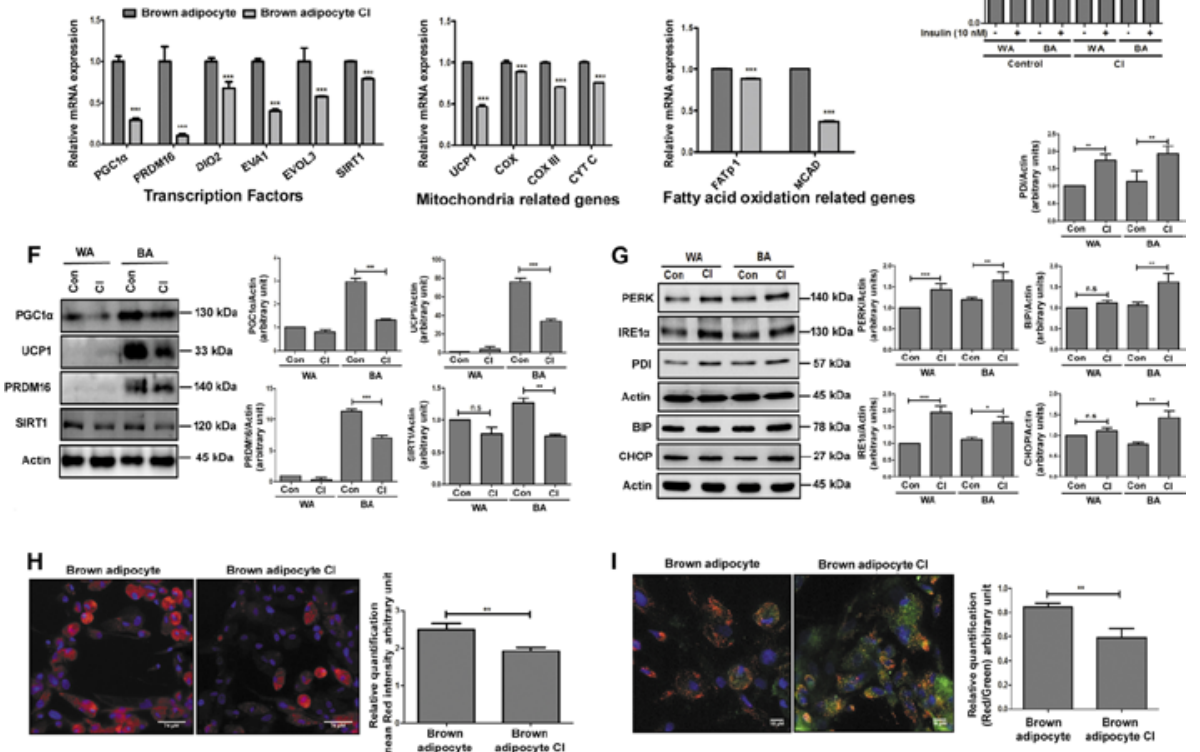

J
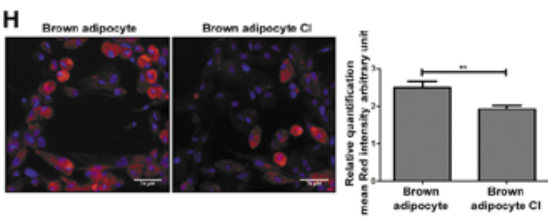

Brown Brown
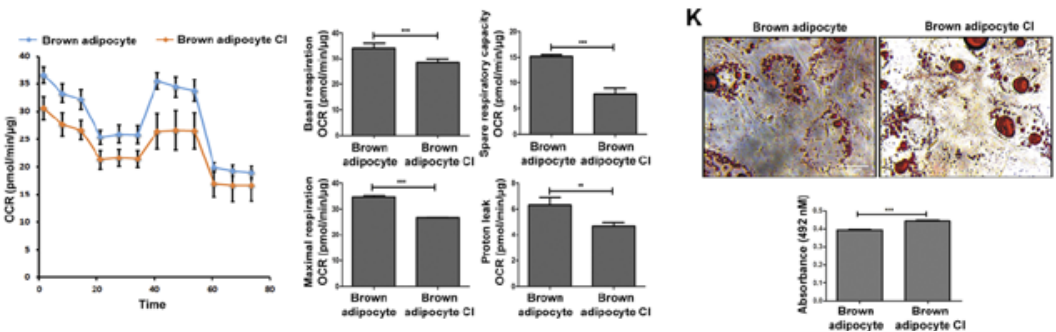

Figure 3

Chronic insulin treatment decreases expression of brown adipocyte-specific markers and leads to insulin resistance in brown adipocytes. White and brown adipocytes were given $\mathrm{Cl}$ treatment as indicated in figure (A). $10 \mathrm{nM}$ insulin stimulation was given before glucose uptake. Glucose uptake reading was normalized to total protein concentration and is represented as fold difference. $n=3$, error bars represent s.D., $* * * P<0.001, * * P<0.01, * P<0.05$ as tested by Student's $t$-test (A). Western blot analysis of p-AKT (Ser473), p-AS160 (Thr 642), and GLUT4 in white and brown adipocytes with and without Cl treatment as indicated in figure (B). $10 \mathrm{nM}$ insulin stimulation was given for $20 \mathrm{~min}$ before protein isolation. Panel adjacent to the blots show the densitometry of protein normalized with respective total protein and actin in case of GLUT4. $n=3$, error bars denote s.D., $* * * P<0.001$ and $* * P<0.01$ as compared by one-way ANOVA and Bonferroni post-test analysis (B). Real-time PCR analysis of brown adipocyte-specific marker genes, genes related to mitochondrial biogenesis, and fatty acid oxidation. $n=3$, error bars represent S.D., $* * * P<0.001$ as tested by two-way ANOVA and Bonferroni's post-test analysis (C, D and E). Western blot analysis of PGC1 $\alpha$, UCP1, PRDM16, and SIRT1 in white and brown adipocytes with and without $\mathrm{Cl}$ treatment as shown in figure (F). The graphs adjacent to the blots show densitometry of the respective proteins normalized with actin. $n=3$, error bars represent s.D., $* * * P<0.001$ as tested with Student's $t$-test (F). Western blot analysis of protein related to ER stress PERK, IRE1 $\alpha$, PDI, BIP, and CHOP in control and Cl-treated white and brown adipocytes. The graphs adjacent to the blots show densitometry of respective proteins normalized with actin. $n=3$, error bars indicate S.D., $* * * P<0.001, * * P<0.01$ and $* P<0.05$ as tested by Student's $t$-test (G). Brown adipocytes were grown in 96 -well eppendroff clear bottom imaging plate and $\mathrm{Cl}$ treatment was given for $72 \mathrm{~h}$ before staining with JC-1 dye. Cells were excited with 405 or $488 \mathrm{nM}$ and image was taken at $20 \times$ magnification using Cellomics (high-content screening platform). Images were analyzed using Image J software. The red fluorescence shoes high-membrane potential mitochondria ( $\mathrm{J}$ aggregates) and green florescence shows low-membrane potential mitochondria ( $\mathrm{L}$ monomers). The graph on the right-hand side is the relative quantification of red to green ratio normalized with nuclear stain DAPI. $n=3$, the error bars denote s.D., $* * * P<0.001$ as tested by Student's $t$-test (H). Similar to the above experiment, brown and brown $\mathrm{Cl}(72 \mathrm{~h})$-treated adipocytes were stained with TMRE dye. Cells were excited at $405 \mathrm{nM}$ and image was taken at $10 \times$ using Cellomics (high-content screening platform). The graph besides the image shows the relative quantification of mean red intensity normalized with DAPI. $n=3$, error bars represent S.D., $* * * P<0.001$ as tested by Student's $t$-test (I). The oxygen consumption rates (OCR) of brown and brown $\mathrm{Cl}(72 \mathrm{~h})$-treated adipocytes at basal level and in the presence of ATP synthase inhibitor ( $1 \mu \mathrm{M}$ oligomycin), proton uncoupler ( $1 \mu \mathrm{M} \mathrm{FCCP),} \mathrm{and} \mathrm{electron} \mathrm{transport} \mathrm{chain} \mathrm{inhibitors} \mathrm{(} 0.5 \mu \mathrm{M}$ rotenone/ antimycin mix) was measured with Seahorse Bioscience XFp Extracellular Flux analyzer, $n=3$, error bars represent S.D., **P<0.005, $* * * P<0.001$ as tested by Student's $t$-test $(\mathrm{J})$. Oil red $\mathrm{O}$ image of brown adipocytes with and without $72-\mathrm{h} \mathrm{Cl}$ treatment taken with Leica DFC450 C microscope at $40 \times$ magnification. The graph besides the image shows the relative oil red $\mathrm{O}$ absorbance at $492 \mathrm{nM} . n=3$, error bars indicate s.D., $* * \star P<0.001$ as tested by Student's $t$-test (K). 
stress-related proteins PERK, IREalpha, PDI, BIP, and CHOP in CI-treated white and brown adipocytes (Fig. 3G). To assess whether the previous results translate to mitochondria biogenesis and functioning, we stained the CI-treated brown adipocytes with JC- 1 and TMRE dye. TMRE staining indicates decreased mitochondrial content in IR brown adipocytes (Fig. 3H). The number of functionally active mitochondria was also significantly decreased in CI-treated brown adipocytes (Fig. 3I). Mitochondrial respiration rate measured in terms of OCR using extracellular flux analyzer further validated the decrease in functionally active mitochondria in CI treated brown adipocytes. The decreases in basal and maximal respiration on CI treatment in brown adipocytes indicate decrease in mitochondrial content. Spare respiratory capacity and proton leak were also significantly reduced on CI treatment, depicting functionally impaired mitochondria (Fig. 3J). We further analyzed the morphological changes induced by CI on brown adipocytes. There was significant increase in lipid accumulation with increase in droplet size on CI treatment in brown adipocytes (Fig. 3K). The above results indicate that hyperinsulinemia affects brown adipocyte functions and are susceptible to insulin resistance similar to white adipocytes.

\section{Chronic insulin exposure increased obesity and induces insulin resistance in C57BL/6 mice}

To verify the in vitro findings, we next investigated whether CI exposure affects insulin sensitivity and glucose metabolism in vivo in C57BL/6 mice. To do this, the mini-osmotic pumps filled with saline or long-acting insulin analogue glargine (0.6U/day) were implanted subcutaneously for 8 weeks (hereafter referred as CI treatment). The continuous chronic exposure of insulin increased body weight gain and weight of eWAT (Fig. 4A and $\mathrm{B})$. We found increased fat mass without any change in lean mass on CI-treated C57BL/6 mice (Fig. 4C and $\mathrm{D})$. Moreover, glucose tolerance and insulin tolerance (GTT and ITT) tests revealed profound increase in glucose intolerance with decreased insulin sensitivity (Fig. 4E and F). In parallel to the above findings, we also found increased level of serum insulin and lipid profile in CI-treated animals (Fig. 4G and H). To determine whether the chronic insulin treatment affects insulin signaling in adipose tissue, we investigated phosphorylation levels of AKT and AS160 in eWAT. CI exposure leads to decreased phosphorylation of both AKT (Ser 473) and AS160 (Thr 642) in eWAT (Fig. 4I). Collectively, CI treatment in mice leads to reduced insulin sensitivity and impaired glucose metabolism.

\section{Hyperinsulinemia reduces insulin sensitivity, characteristics, and functioning of brown adipose tissue}

It is well recognized that reduced energy expenditure is associated with enhanced obesity and thereby insulin resistance. Thus, we next investigated the role of hyperinsulinemia on energy expenditure by indirect calorimetric analysis. Indeed, CI treatment in mice increased food intake and decreased locomotor activity (Fig. 5A and B). CI-treated mice also showed less $\mathrm{O}_{2}$ consumption and $\mathrm{CO}_{2}$ production compared with saline-treated mice (Fig. 5C and D). Consistent with the reduced $\mathrm{VO}_{2}$ and $\mathrm{VCO}_{2}$, CI-treated mice have less metabolic rate and generated less heat compared with saline-treated mice (Fig. 5E and F). Taking clues from the in vitro findings and energy expenditure studies, we were keen to validate and further study the effect of CI on BAT. We found that CI treatment leads to decreased insulin-stimulated phosphorylation of AKT (Ser 473) and AS160 (Thr 642) and with less expression of Glut4 in iBAT (Fig. 5G). Literature suggests that UCP1, PRDM16, and PGC1 $\alpha$ negatively regulate obesity and metabolic syndrome (Liang \& Ward 2006, Kozak \& Anunciado-Koza 2008, Feldmann et al. 2009, Becerril et al. 2013). To assess whether the decreased insulin sensitivity in CI-treated animals also affects brown adipose markers in iBAT, we analyzed mRNA expression of brown adipocyte-specific genes involved in mitochondrial biogenesis and fatty acid oxidation. The continuous exposure of insulin decreased the mRNA expression of brown adipocyte-specific transcription factors such as Prdm16, SirT1, Dio2, and Pgc1 $\alpha$ in iBAT (Fig. $5 \mathrm{H}$ ). The decrease in expression of mitochondrial biogenesis and fatty acid oxidation-related genes such as Atp5G, Cox IV, Cox III, Ucp1, Fatp1, and Mcad in iBAT of CI-treated animals suggests decreased metabolic activity and loss of uncoupling property (Fig. 5I and J). We have also validated expression of UCP1, PGC1 $\alpha$, SDH, and PRDM16 at protein level (Fig. 5K). Decreases in mitochondrial biogenesis and fatty acid oxidation are well implicated in obesity and metabolic disorders. The above results suggest that hyperinsulinemia not only reduces brown adipocyte capacity to utilize fatty acid via uncoupled respiration but also diminishes brown adipocyte characteristics, making it susceptible to

Published by Bioscientifica Ltd. 

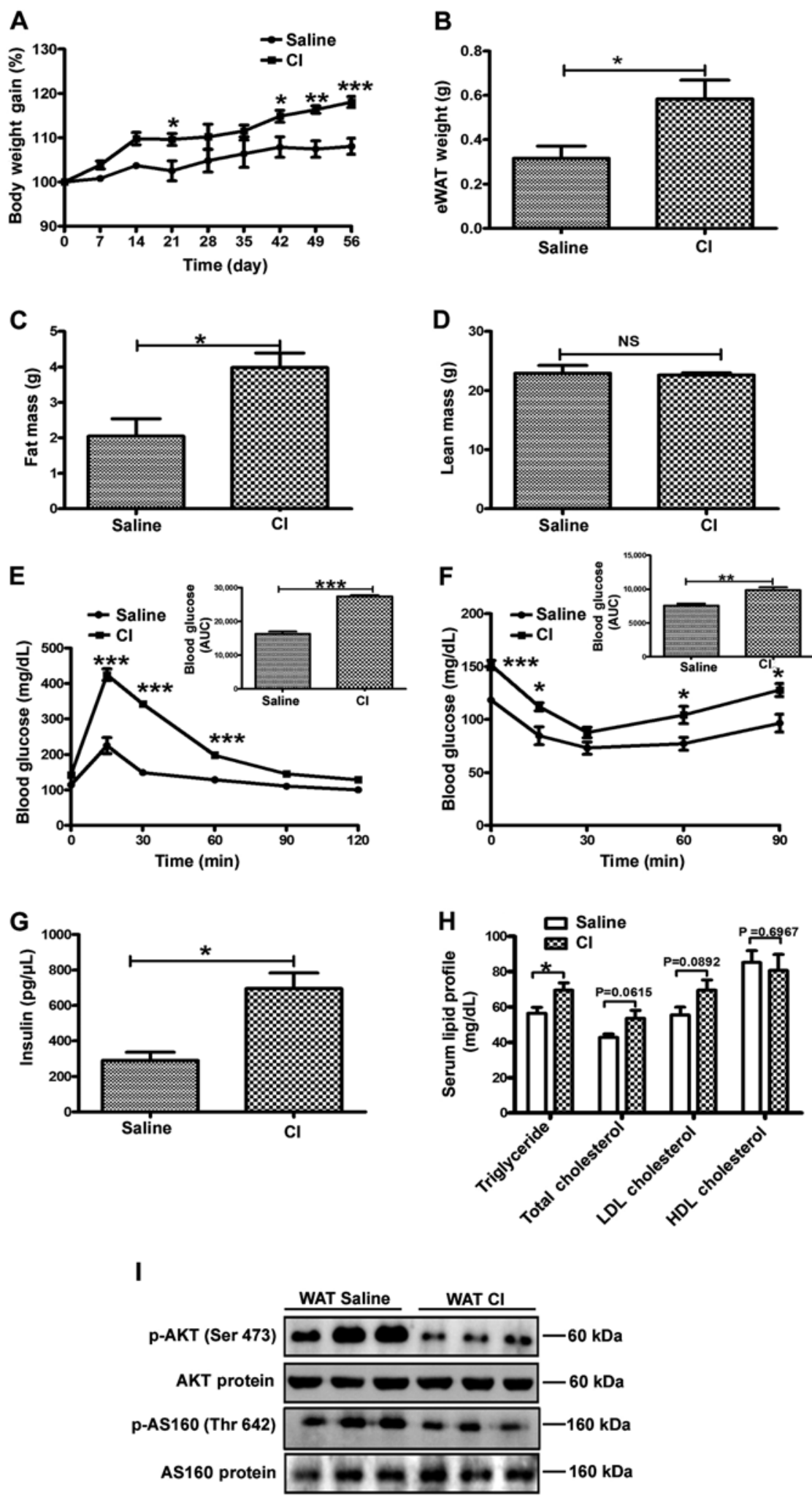

\section{Figure 4}

Chronic insulin exposure increased obesity and insulin resistance in C57BL/6 mice. Body weight gain of saline- and $\mathrm{Cl}$-treated C57BL/6 mice monitored up to 8 weeks. $n=6$, error bars represent S.D., $* P<0.05, * * P<0.01, * * * P<0.001$ as tested by two-way ANOVA and Bonferroni's post-test analysis (A). Epididymal white adipose tissue weight of saline- and Cl-treated C57BL/6 mice were taken after killing. $n=6$, error bars indicates S.D., ${ }^{*} P<0.05, * * P<0.01, * * * P<0.001$ as tested by Student's $t$-test (B). Total fat and lean mass of saline- and $\mathrm{Cl}$-treated $\mathrm{C} 57 \mathrm{BL} / 6$ mice were assessed using Echo MRI after 8 weeks. $n=6$, error bars represent S.D., ${ }^{*} P<0.05, * * P<0.01$,

$* * * P<0.001$ as tested by Student's $t$-test ( $C$ and $D$ ). Glucose tolerance was assessed by IPGTT and glucose profiles calculated from IPGTT as area under the curve (E). Insulin tolerance was assessed by ITT and glucose profile calculated from ITT as area under the curve (F). Serum insulin, triglyceride, total cholesterol, LDL-cholesterol, and HDL-cholesterol were measured in 6-h fasted animals ( $\mathrm{G}$ and $\mathrm{H}$ ). ${ }^{* * P} P<0.01, * * * P<0.001$ as tested by two-way ANOVA and Bonferroni's post-test analysis. Proteins isolated from subcutaneous WAT of three control and Cl-treated C57BL/6 mice were subjected to western blot analysis for p-AKT (Ser473) and p-AS160 (Thr 642). The total level of respective proteins is given bellow each blot (I). insulin resistance. To gain further insights into how CI treatment impairs insulin sensitivity and functioning of BAT, we investigated inflammatory and ER stress-associated marker. We found increased expression of inflammatory markers (TNF $\alpha$, IL6, and F4/80) in CI-treated mice (Fig. 5L). CI treatment also increased 
A
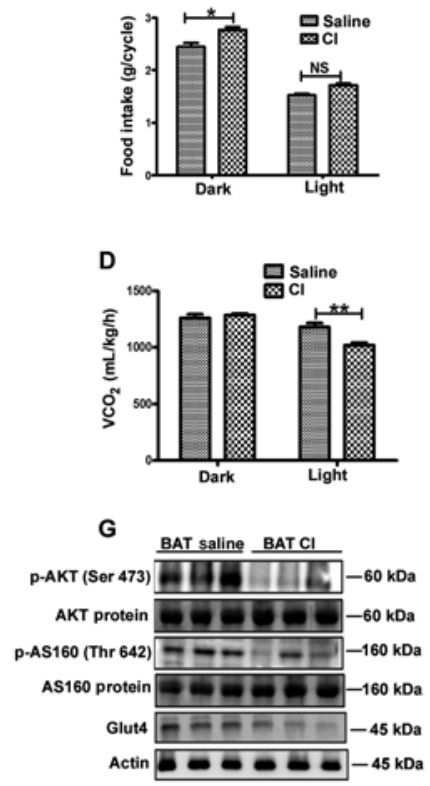

B

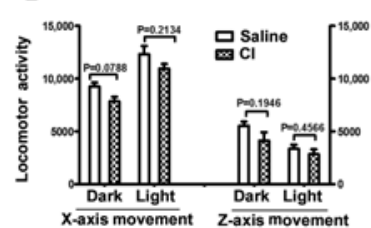

E

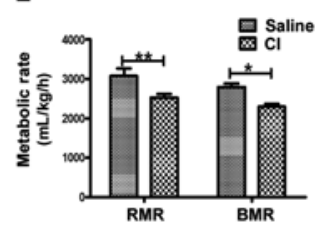

H

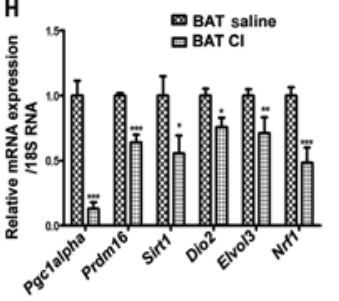

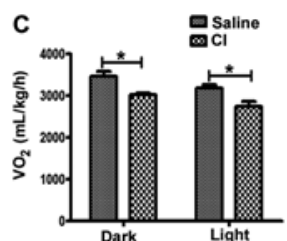

F

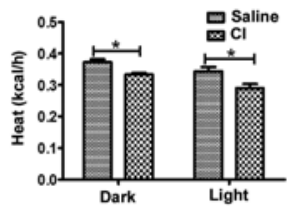

I

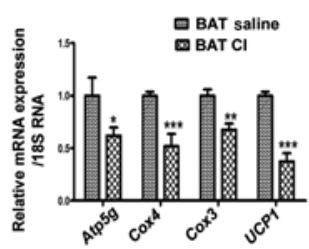

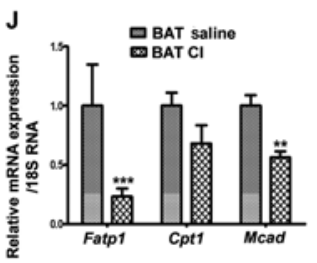

K

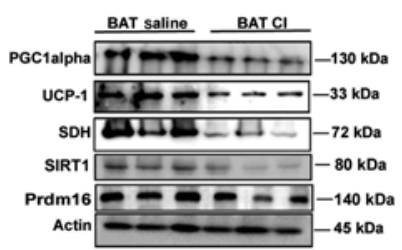

L

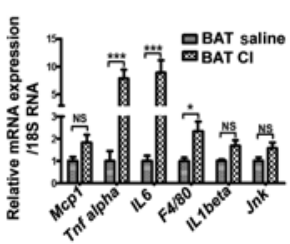

M

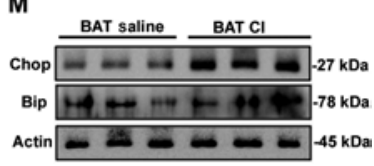

Figure 5

Hyperinsulinemia reduces insulin sensitivity in brown adipose tissue and affects characteristic and functioning of BAT. Food intake during CLAMS (A) locomotor activity (B), volume of $\mathrm{O}_{2}$ consumption (C), $\mathrm{CO}_{2}$ production (D), metabolic rate (E), and heat production (F). Data from figure $A-\mathrm{F}$ were taken and analyzed from CLAMS studies. The data represented here are mean of 6 days, $n=6$, error bars indicate s.D., $* P<0.05$, $* * P<0.01, * * * P<0.001$ as tested by Student's $t$-test analysis. Western blot analysis of p-AKT (Ser473), p-AS160 (Thr 642), and Glut4 protein expression was done in protein isolated from interscapular BAT of three control and Cl-treated C57BL/6 mice along with their total level of respective proteins, $n=3$ (G). Real-time PCR analysis of brown adipocyte-specific markers, genes involved in mitochondrial biogenesis, and fatty acid oxidation in interscapular BAT of control and Cl-treated C57BL/6 mice. $n=3$, error bars represent s.D., $* P<0.05, * * P<0.01, * * * P<0.001$ as tested by one-way ANOVA and Bonferroni's post-test analysis $(\mathrm{H}, \mathrm{I}$ and $\mathrm{J})$. Western blot analysis of PGC1 $\alpha, \mathrm{UCP} 1, \mathrm{SIRT1}$, and SDH in protein isolated from interscapular BAT of three control and $\mathrm{Cl}$-treated mice, $n=3$ (K). Real-time PCR analysis of inflammatory markers in interscapular BAT of control and Cl-treated C57BL/6 mice. $n=3$, error bars represent s.E.M., ${ }^{*} P<0.05, * * P<0.01, * * * P<0.001$ as tested by two-way ANOVA and Bonferroni's post-test analysis (L). Western blot analysis of Chop and Bip in protein isolated from interscapular BAT of three control and Cl-treated mice, $n=3(\mathrm{M})$.

expression of ER stress markers Chop and Bip at protein level. These data suggest that part of impaired insulin sensitivity and functioning of BAT in CI-treated mice might be due to ER stress and inflammation.

\section{Discussion}

Hyperinsulinemia is considered as a common factor among the metabolic syndrome including obesity and diabetes (Butler et al. 1990, Kim et al. 2015b). A number of studies have reported that hyperinsulinemia alone is sufficient to cause/drive insulin resistance (Rizza et al. 1985, Kahn \& Flier 2000, Yang et al. 2014, Pedersen et al. 2015). Moreover, hyperglycemia (Liu et al. 2009), free fatty acids (Ning et al. 2011), or the amino acids (Zhang et al. 2007) alone are insufficient to induce insulin resistance. Clinical and rodent studies have successfully correlated decrease in BAT volume with increased body mass index (BMI), but remained to be explored the detailed inter-relationship. All obese animal models show defective BAT activity and lower level of UCP1 expression (Ferre et al. 1986, Yoneshiro et al. 2011). Thus, it was logical to study the effect of hyperinsulinemia on 
BAT function. Various in vitro insulin resistance models of white adipocytes have been reported in the literature to study the disease pathophysiology. Recent advancement in stem cell research and the feasibility to differentiate human adipose-derived stem cells (hADSCs) to white and brown adipocytes have made hADSC as a desired model to study adipocyte biology (DeLany et al. 2005). Obese prediabetic subjects have been reported to have 400$600 \mathrm{pM} / \mathrm{L}$ serum insulin and $7-11 \mathrm{mmol} / \mathrm{L}$ of blood glucose (Dileepan \& Feldt 2013). Recently, Guanfeng Xu and coworkers exposed human primary adipocytes to $600 \mathrm{pM}$ insulin $/ 25 \mathrm{mM}$ glucose for $48 \mathrm{~h}$ to induce insulin resistance (Xu et al. 2015). This inspired us to develop IR adipocyte model by decreasing the insulin exposure concentration to $500 \mathrm{pM}$ and glucose $10 \mathrm{mM}$ for $72 \mathrm{~h}$ to corroborate with pathophysiological level. Our results showed that hMSCderived both white and brown adipocytes developed insulin resistance on chronic exposure to $500 \mathrm{pM}$ insulin for $72 \mathrm{~h}$ and collate very well with the findings of $\mathrm{Xu}$ and coworkers (Fig. 1H). hMSC-derived white adipocyte is increasingly being used to study insulin resistance, but there is still considerable knowledge gap in context of brown adipocytes and hyperinsulinemia-induced insulin resistance. Recently, two independent research groups have reported differentiation of mesenchymal stem cells into functionally active brown adipocytes (Pisani et al. 2011, Ahfeldt et al. 2012). These differentiated adipocytes showed all the distinct characteristics of brown adipocytes such as increased expression of PRDM16, PGC1 $\alpha$, UCP1, and high mitochondrial content (Fig. 2B, C, D, E, F, G and $\mathrm{H})$. This also extended us the opportunity to probe the effect of hyperinsulinemia on brown adipocytes. Our in vitro results suggest that hyperinsulinemia reduces insulin sensitivity of brown adipocytes by decreasing brown adipocyte-specific characteristics such as expression of UCP1, PGC1 $\alpha$, mitochondrial biogenesis, and spare respiratory capacity, which signifies the metabolic activity of mitochondria. Study conducted by Ruidan Xue and coworkers have used spare respiratory capacity to characterize biomarkers with thermogenic potential with strong correlation with UCP1 expression (Xue et al. 2015). The decrease in spare respiratory capacity and proton leak in IR brown adipocytes confirms the loss of uncoupling function, which may be due to decrease in UCP1 expression (Fig. 3D and F).

Taking clues from these studies, we developed insulin resistance model in vivo in C57BL/6 mice. Excess energy intake plays an important role in causing obesity and insulin resistance (Frederich et al. 1995, Considine et al. 1996). CI treatment for 8 weeks in mice increased nocturnal food intake significantly. We have also observed increased hypertrophied adipose tissue mass after completion of treatment period. Hypertrophied adipocytes are known to secrete increased leptin, which in turn causes leptin resistance (Ren 2004, Knight et al. 2010). The cumulative outcome, although it does not clarify cause or effect, but results into increased food intake as reflected in our studies. Consistent with the previous studies, chronic insulin treatment in C57BL/6 mice leads to increased obesity and decreased insulin sensitivity (Fig. 4A, B, C, D, E, F, G, H and I). Surprisingly, we also found that $\mathrm{CI}$ treatment in brown adipocytes significantly reduced insulin sensitivity (Fig. 5G), expression of brown adipocyte-specific genes (Fig. 5H, I and J), and decreased mitochondrial content and function (Fig. 5K). CI treatment also led to decrease in mitochondrial respiration and proton leak in hMSC-derived brown adipocytes (Fig. 3J), energy expenditure (Fig. 5C, D and $\mathrm{E}$ ), heat production in vivo (Fig. $5 \mathrm{~F}$ ), thereby affecting the function of brown adipocytes. Our studies concludes that although brown adipose tissue has been known to protect from diet-induced obesity and improve insulin sensitivity, but in continuous hyperinsulinemic milieu as observed in clinical setups, brown adipocyte capacity to utilize the excess energy is compromised. The above results, to certain extent, explain the negative correlation of functionally active brown adipose tissue with increase in BMI. Negative correlation between decreases in brown fat content with increase in BMI is well reported except in context of the effects of hyperinsulinemia on the trans/ differentiation and functional aspects of BAT. BAT activity has been detected in lean person with low fasting blood glucose level and show negative correlation with increase in BMI (Lee et al. 2010). Clinical study conducted by Orva and coworkers showed that brown adipose tissue in obese subject does not respond to cold and insulin stimulation (Orava et al. 2013). Similar results were also observed in 18FDG-PET/CT scan study by Pfannenberg et al. (2010). The decrease in basal and resting metabolic rate along with heat production in CI-treated animals further strengthens the in vitro results and our hypothesis. Our results can be interpreted in concordance to the in vivo studies conducted by different group in obese subjects depicting to have defective BAT function (Heilbronn et al. 2007, Kim et al. 2015). Hyperinsulinemia has been reported to cause mitochondrial dysfunction in white adipocytes, muscle, and heart through generation of reactive oxygen species, free radicals, and ER stress. Earlier Shabalina and coworkers have reported the effect of reactive oxygen species (ROS) in overall functioning of brown adipocytes

Published by Bioscientifica Ltd. 
(Shabalina et al. 2014). We found increased expression of ER stress markers in BAT of both in vitro and in vivo CI conditions (Figs. 3G and 5M). Another interesting observation is the significant increase in the expression of pro-inflammatory markers such as Tnfo, IL6, and F4/80 in BAT micro milieu of CI-treated animals (Fig. 5L). All these results give possible explanation to decreased activity of BAT function and characteristics upon CI treatment, but may not be implicated for changed BAT phenotype. Our results collates very well with the study conducted by Matamala and coworkers, where authors have demonstrated that lack of BAT response in obese rat is due to the change in mitochondria subpopulation and it was different from lean rat (Matamala et al. 1996). The above literature provides coherent evidence to suggest that CI treatment may also change the mitochondrial subpopulation leading to decrease the metabolic activity of brown adipocytes. Loss of uncoupling property on CI treatment will lead to less utilization of lipid droplets and increase lipid accumulation (hypertrophy), which makes brown adipocytes susceptible to insulin resistance.

Our in vitro and in vivo results suggest that development of insulin resistance in brown adipocytes is associated with decrease in expression of brown adipocyte markers and loss of uncoupling property (Fig. 5A, B, C, D, E, F, G, H, I, J, K, L and M). Recent study demonstrated that high-fat diet-fed C57BL/6 mice show increased lipid droplet accumulation in brown adipose tissue and insulin resistance (Roberts-Toler et al. 2015). The study conducted by Mehran and coworkers showed that Ins1+/- and Ins2-/knockdown mice have increased energy expenditure and lipid mobilization resulting from increased UCP1 expression at both mRNA and protein level. One of the mechanisms suggested for increased UCP1 expression is increased sympathetic activity in Ins $1^{+/-}$and Ins2 $2^{-/-}$ knockdown mice (Mehran et al. 2012). From these studies, it is rational to conclude that peripheral hyperinsulinemia plays a negative role in UCP1 expression. Other report indicates that the expression of UCP1 is dependent on SIRT1-mediated deactylation of PPAR gamma (Qiang et al. 2012). We found decreased expression of SIRT 1 in CI-treated white and brown adipocytes, which may act as a possible connecting link between insulin and UCP1 expression. The excess ectopic lipid accumulation has deleterious effect leading to inhibition of genes involved in mitochondrial biogenesis and thermogenesis. Many studies have reported reduced thermogenesis in HFD-fed obese rodents. Oil red $\mathrm{O}$ staining of IR brown adipocytes yielded similar results as mentioned above, and there was a significant increase in lipid accumulation (Fig. 3K).
BAT of genetically obese ob/ob mice show insulin resistance and reduced cold-induced activation of thermogenesis (Thurlby \& Trayhurn 1980). In concurrence, our studies imply the role of hyperinsulinemia in defective BAT function in obese subjects. Vascular refraction has been shown to mediate whitening of brown adipocyte due to hypoxia (Shimizu et al. 2014). Even though increase in lipid accumulation and decrease in brown adipocyte characteristics are evident from our results, it will be inconclusive to suggest whitening of brown adipocytes. As human brown fat is known to possess molecular signatures similar to white adipocytes (Sharp et al. 2012), it is not surprising to observe the adaptation of BAT according to the physiological needs.

In conclusion, we for the first time here with report that hyperinsulinemia reduces insulin sensitivity of brown adipocytes both in vitro and in vivo conditions. Our study also confirms the negative correlation of BAT function along with decrease in mitochondrial content and respiration with hyperinsulinemia. Our study has greater implication in respect to use of brown adipocyte for the treatment of insulin resistance and related metabolic syndrome. Our findings imply that browning alone may not be sufficient to permanently revert insulin resistance as its effect dissipates in hyperinsulinemic obese micro milieu on longer run. Above results compel us to re-evaluate the strategy of recruiting brown adipocyte for the treatment of obesity and insulin resistance unless beforehand we correct micro milieu.

Declaration of interest

The authors declare that there is no conflict of interest that could be perceived as prejudicing the impartiality of the research reported.

\section{Funding}

This research work is supported by the Department of Biotechnology and Department of Science and Technology DBT Government of India Project GAP1079, CSIR-CDRI Network project: "Towards holistic understanding of complex diseases: Unraveling the threads of complex disease (THUNDER)", Project No: BSC0102 and project Understanding of disease dynamics and to accelerate drug discovery. Project No: UNDO-BSC0103.

\section{Acknowledgment}

We acknowledge the help provided by Prof. Nuzhat Husain (Director), Dr Ram ManoharLohia, Institute of Medical Science, for approval from stem cell ethics committee. We also acknowledge the help and support provided by staff of the Sushrut Institute of Plastic Surgery (SIPS) Hospital for collection of liposuction sample. We acknowledge the help provided by A L Vishwakarma and staffs in the Sophisticated Analytical Instrumentation Facility (SAIF) in performing flow cytometry experiments. Research work is supported by the CSIR-CDRI Network project: "Towards holistic understanding of complex diseases: Unraveling the threads of

Published by Bioscientifica Ltd. 
complex disease (THUNDER)", Project No: BSC0102 and by the Department of Biotechnology (DBT) project (GAP0179). MB is supported by S R F D B T; $S R, A G$, and $K S$ are supported by SRF-UGC; D K and A S are supported by SRF-CSIR, New Delhi. S V is supported by THUNDER project. This manuscript bears CSIR-CDRI manuscript number: 9262

\section{References}

Ahfeldt T, Schinzel RT, Lee YK, Hendrickson D, Kaplan A, Lum DH, Camahort R, Xia F, Shay J, Rhee EP, et al. 2012 Programming human pluripotent stem cells into white and brown adipocytes. Nature Cell Biology 14 209-219. (doi:10.1038/ncb2411)

Becerril S, Gomez-Ambrosi J, Martin M, Moncada R, Sesma P, Burrell MA \& Fruhbeck G 2013 Role of PRDM16 in the activation of brown fat programming. Relevance to the development of obesity. Histology and Histopathology 28 1411-1425. (doi:10.14670/HH-28.1411)

Beg M, Shankar K, Varshney S, Rajan S, Singh SP, Jagdale P, Puri A, Chaudhari BP, Sashidhara KV \& Gaikwad AN 2015 A clerodane diterpene inhibit adipogenesis by cell cycle arrest and ameliorate obesity in C57BL/6 mice. Molecular and Cellular Endocrinology 399 373-385. (doi:10.1016/j.mce.2014.09.024)

Cinti S 2012 The adipose organ at a glance. Disease Models and Mechanisms 5 588-594. (doi:10.1242/dmm.009662)

Considine RV, Sinha MK, Heiman ML, Kriauciunas A, Stephens TW, Nyce MR, Ohannesian JP, Marco CC, McKee LJ, Bauer TL, et al. 1996 Serum immunoreactive-leptin concentrations in normal-weight and obese humans. New England Journal of Medicine 334 292-295. (doi:10.1056/NEJM199602013340503)

Cypess AM, Lehman S, Williams G, Tal I, Rodman D, Goldfine AB, Kuo FC, Palmer EL, Tseng YH, Doria A, et al. 2009 Identification and importance of brown adipose tissue in adult humans. New England Journal of Medicine 360 1509-1517. (doi:10.1056/NEJMoa0810780)

DeLany JP, Floyd ZE, Zvonic S, Smith A, Gravois A, Reiners E, Wu X, Kilroy G, Lefevre M \& Gimble JM 2005 Proteomic analysis of primary cultures of human adipose-derived stem cells: modulation by adipogenesis. Molecular and Cellular Proteomics 4 731-740. (doi:10.1074/mcp.M400198-MCP200)

Dileepan K \& Feldt MM 2013 Type 2 diabetes mellitus in children and adolescents. Pediatrics in Review 34 541-548. (doi:10.1542/pir.34-12-541)

Elabd C, Chiellini C, Carmona M, Galitzky J, Cochet O, Petersen R, Penicaud L, Kristiansen K, Bouloumie A, Casteilla L, et al. 2009 Human multipotent adipose-derived stem cells differentiate into functional brown adipocytes. Stem Cells 27 2753-2760. (doi:10.1002/ stem.200)

Erdmann J, Kallabis B, Oppel U, Sypchenko O, Wagenpfeil S \& Schusdziarra V 2008 Development of hyperinsulinemia and insulin resistance during the early stage of weight gain. American Journal of Physiology: Endocrinology and Metabolism 294 E568-E575. (doi:10.1152/ajpendo.00560.2007)

Feldmann HM, Golozoubova V, Cannon B \& Nedergaard J 2009 UCP1 ablation induces obesity and abolishes diet-induced thermogenesis in mice exempt from thermal stress by living at thermoneutrality. Cell Metabolism 9 203-209. (doi:10.1016/j.cmet.2008.12.014)

Ferre P, Burnol AF, Leturque A, Terretaz J, Penicaud L, Jeanrenaud B \& Girard J 1986 Glucose utilization in vivo and insulin-sensitivity of rat brown adipose tissue in various physiological and pathological conditions. Biochemical Journal 233 249-252. (doi:10.1042/bj2330249)

Frederich RC, Hamann A, Anderson S, Lollmann B, Lowell BB \& Flier JS 1995 Leptin levels reflect body lipid content in mice: evidence for diet-induced resistance to leptin action. Nature Medicine 1 1311-1314. (doi:10.1038/nm1295-1311)

Gray SL, Donald C, Jetha A, Covey SD \& Kieffer TJ 2010 Hyperinsulinemia precedes insulin resistance in mice lacking pancreatic beta-cell leptin signaling. Endocrinology 151 4178-4186. (doi:10.1210/en.2010-0102)
Hamann A, Flier JS \& Lowell BB 1996 Decreased brown fat markedly enhances susceptibility to diet-induced obesity, diabetes, and hyperlipidemia. Endocrinology 137 21-29. (doi:10.1210/ en.137.1.21)

Heilbronn LK, Gan SK, Turner N, Campbell LV \& Chisholm DJ 2007 Markers of mitochondrial biogenesis and metabolism are lower in overweight and obese insulin-resistant subjects. Journal of Clinical Endocrinology and Metabolism 92 1467-1473. (doi:10.1210/ jc.2006-2210)

Hermida-Gomez T, Fuentes-Boquete I, Gimeno-Longas MJ, Muinos-Lopez E, Diaz-Prado S, de Toro FJ \& Blanco FJ 2011 Quantification of cells expressing mesenchymal stem cell markers in healthy and osteoarthritic synovial membranes. Journal of Rheumatology 38 339-349. (doi:10.3899/jrheum.100614)

Kahn BB \& Flier JS 2000 Obesity and insulin resistance. Journal of Clinical Investigation 106 473-481. (doi:10.1172/JCI10842)

Kim HS, Ryoo ZY, Choi SU \& Lee S 2015 Gene expression profiles reveal effect of a high-fat diet on the development of white and brown adipose tissues. Gene 565 15-21. (doi:10.1016/j.gene.2015.03.077)

Knight ZA, Hannan KS, Greenberg ML \& Friedman JM 2010 Hyperleptinemia is required for the development of leptin resistance. PLOS ONE 5 e11376. (doi:10.1371/journal.pone.0011376)

Kozak LP \& Anunciado-Koza R 2008 UCP1: its involvement and utility in obesity. International Journal of Obesity 32 (Supplement 7) S32-S38. (doi:10.1038/ijo.2008.236)

Lee P, Greenfield JR, Ho KK \& Fulham MJ 2010 A critical appraisal of the prevalence and metabolic significance of brown adipose tissue in adult humans. American Journal of Physiology: Endocrinology and Metabolism 299 E601-E606. (doi:10.1152/ajpendo.00298.2010)

Liang H \& Ward WF 2006 PGC-1alpha: a key regulator of energy metabolism. Advances in Physiology Education 30 145-151. (doi:10.1152/advan.00052.2006)

Liu HY, Cao SY, Hong T, Han J, Liu Z \& Cao W 2009 Insulin is a stronger inducer of insulin resistance than hyperglycemia in mice with type 1 diabetes mellitus (T1DM). Journal of Biological Chemistry 284 27090-27100. (doi:10.1074/jbc.M109.016675)

Liu X, Zheng Z, Zhu X, Meng M, Li L, Shen Y, Chi Q, Wang D, Zhang Z, Li C, et al. 2013 Brown adipose tissue transplantation improves whole-body energy metabolism. Cell Research 23 851-854. (doi:10.1038/cr.2013.64)

Lowell BB, S-Susulic V, Hamann A, Lawitts JA, Himms-Hagen J, Boyer BB, Kozak LP \& Flier JS 1993 Development of obesity in transgenic mice after genetic ablation of brown adipose tissue. Nature 366 740-742. (doi:10.1038/366740a0)

Matamala JC, Gianotti M, Pericas J, Quevedo S, Roca P, Palou A \& Garcia-Palmer FJ 1996 Changes induced by fasting and dietetic obesity in thermogenic parameters of rat brown adipose tissue mitochondrial subpopulations. Biochemical Journal 319 529-534. (doi:10.1042/bj3190529)

Mehran AE, Templeman NM, Brigidi GS, Lim GE, Chu KY, Hu X, Botezelli JD, Asadi A, Hoffman BG, Kieffer TJ, et al. 2012 Hyperinsulinemia drives diet-induced obesity independently of brain insulin production. Cell Metabolism 16 723-737. (doi:10.1016/ j.cmet.2012.10.019)

Ning J, Hong T, Yang X, Mei S, Liu Z, Liu HY \& Cao W 2011 Insulin and insulin signaling play a critical role in fat induction of insulin resistance in mouse. American Journal of Physiology: Endocrinology and Metabolism 301 E391-E401. (doi:10.1152/ajpendo.00164.2011)

Orava J, Nuutila P, Noponen T, Parkkola R, Viljanen T, Enerback S, Rissanen A, Pietilainen KH \& Virtanen KA 2013 Blunted metabolic responses to cold and insulin stimulation in brown adipose tissue of obese humans. Obesity 21 2279-2287. (doi:10.1002/oby.20456)

Ouellet V, Routhier-Labadie A, Bellemare W, Lakhal-Chaieb L, Turcotte E, Carpentier AC \& Richard D 2011 Outdoor temperature, age, sex, body mass index, and diabetic status determine the prevalence, mass, and glucose-uptake activity of 18F-FDG-detected BAT in humans. 
Journal of Clinical Endocrinology and Metabolism 96 192-199. (doi:10.1210/jc.2010-0989)

Pedersen DJ, Guilherme A, Danai LV, Heyda L, Matevossian A, Cohen J, Nicoloro SM, Straubhaar J, Noh HL, Jung D, et al. 2015 A major role of insulin in promoting obesity-associated adipose tissue inflammation. Molecular Metabolism 4 507-518. (doi:10.1016/ j.molmet.2015.04.003)

Pfannenberg C, Werner MK, Ripkens S, Stef I, Deckert A, Schmadl M, Reimold M, Haring HU, Claussen CD \& Stefan N 2010 Impact of age on the relationships of brown adipose tissue with sex and adiposity in humans. Diabetes 59 1789-1793. (doi:10.2337/db10-0004)

Pisani DF, Djedaini M, Beranger GE, Elabd C, Scheideler M, Ailhaud G \& Amri EZ 2011 Differentiation of human adipose-derived stem cells into "brite" (brown-in-white) adipocytes. Frontiers in Endocrinology 2 87. (doi:10.3389/fendo.2011.00087)

Qiang L, Wang L, Kon N, Zhao W, Lee S, Zhang Y, Rosenbaum M, Zhao Y Gu W, Farmer SR, et al. 2012 Brown remodeling of white adipose tissue by SirT1-dependent deacetylation of Ppargamma. Cell 150 620-632. (doi:10.1016/j.cell.2012.06.027)

Ren J 2004 Leptin and hyperleptinemia - from friend to foe for cardiovascular function. Journal of Endocrinology 181 1-10. (doi:10.1677/joe.0.1810001)

Rizza RA, Mandarino LJ, Genest J, Baker BA \& Gerich JE 1985 Production of insulin resistance by hyperinsulinaemia in man. Diabetologia $\mathbf{2 8}$ 70-75. (doi:10.1007/BF00279918)

Roberts-Toler C, O’Neill BT \& Cypess AM 2015 Diet-induced obesity causes insulin resistance in mouse brown adipose tissue. Obesity $\mathbf{2 3}$ 1765-1770. (doi:10.1002/oby.21134)

Sashidhara KV, Singh SP, Varshney S, Beg M \& Gaikwad AN 2014 Poliothrysoside and its derivatives as novel insulin sensitizers potentially driving AMPK activation and inhibiting adipogenesis. European Journal of Medicinal Chemistry 86 570-577. (doi:10.1016/ j.ejmech.2014.09.015)

Shabalina IG, Vrbacky M, Pecinova A, Kalinovich AV, Drahota Z, Houstek J, Mracek T, Cannon B \& Nedergaard J 2014 ROS production in brown adipose tissue mitochondria: the question of UCP1-dependence. Biochimica et Biophysica Acta 1837 2017-2030. (doi:10.1016/j.bbabio.2014.04.005)

Shanik MH, Xu Y, Skrha J, Dankner R, Zick Y \& Roth J 2008 Insulin resistance and hyperinsulinemia: is hyperinsulinemia the cart or the horse? Diabetes Care 31 (Supplement 2) S262-S268. (doi:10.2337/ dc08-s264)

Sharp LZ, Shinoda K, Ohno H, Scheel DW, Tomoda E, Ruiz L, Hu H, Wang L, Pavlova Z, Gilsanz V, et al. 2012 Human BAT possesses molecular signatures that resemble beige/brite cells. PLoS ONE 7 e49452. (doi:10.1371/journal.pone.0049452)
Shimizu I, Aprahamian T, Kikuchi R, Shimizu A, Papanicolaou KN, MacLauchlan S, Maruyama S \& Walsh K 2014 Vascular rarefaction mediates whitening of brown fat in obesity. Journal of Clinical Investigation 124 2099-2112. (doi:10.1172/JCI71643)

Thurlby PL \& Trayhurn P 1980 Regional blood flow in genetically obese (ob/ob) mice. The importance of brown adipose tissue to the reduced energy expenditure on non-shivering thermogenesis. Pflügers Archiv 385 193-201. (doi:10.1007/BF00647457)

Vijgen GH, Bouvy ND, Teule GJ, Brans B, Schrauwen P \& van Marken Lichtenbelt WD 2011 Brown adipose tissue in morbidly obese subjects. PLOS ONE 6 e17247. (doi:10.1371/journal.pone.0017247)

Wajchenberg BL 2000 Subcutaneous and visceral adipose tissue: their relation to the metabolic syndrome. Endocrine Reviews 21 697-738. (doi:10.1210/edrv.21.6.0415)

Xu G, Ji C, Song G, Zhao C, Shi C, Song L, Chen L, Yang L, Huang F, Pang L, et al. 2015 MiR-26b modulates insulin sensitivity in adipocytes by interrupting the PTEN/PI3K/AKT pathway. International Journal of Obesity 39 1523-1530. (doi:10.1038/ijo.2015.95)

Xue R, Lynes MD, Dreyfuss JM, Shamsi F, Schulz TJ, Zhang H, Huang TL, Townsend KL, Li Y, Takahashi H, et al. 2015 Clonal analyses and gene profiling identify genetic biomarkers of the thermogenic potential of human brown and white preadipocytes. Nature Medicine 21 760-768. (doi:10.1038/nm.3881)

Yang X, Mei S, Gu H, Guo H, Zha L, Cai J, Li X, Liu Z \& Cao W 2014 Exposure to excess insulin (glargine) induces type 2 diabetes mellitus in mice fed on a chow diet. Journal of Endocrinology 221 469-480. (doi:10.1530/JOE-14-0117)

Ye J 2013 Mechanisms of insulin resistance in obesity. Frontiers of Medicine 7 14-24. (doi:10.1007/s11684-013-0262-6)

Yoneshiro T, Aita S, Matsushita M, Okamatsu-Ogura Y, Kameya T, Kawai Y, Miyagawa M, Tsujisaki M \& Saito M 2011 Age-related decrease in cold-activated brown adipose tissue and accumulation of body fat in healthy humans. Obesity 19 1755-1760. (doi:10.1038/ oby.2011.125)

Zhang Y, Guo K, LeBlanc RE, Loh D, Schwartz GJ \& Yu YH 2007 Increasing dietary leucine intake reduces diet-induced obesity and improves glucose and cholesterol metabolism in mice via multimechanisms. Diabetes 56 1647-1654. (doi:10.2337/db07-0123)

Zhang Z, Zhang H, Li B, Meng X, Wang J, Zhang Y, Yao S, Ma Q, Jin L, Yang J, et al. 2014 Berberine activates thermogenesis in white and brown adipose tissue. Nature Communications 5 5493. (doi:10.1038/ ncomms6493)

Zuk PA, Zhu M, Ashijian P, De Ugarte DA, Huang JI, Mizuno H, Alfonso ZC, Fraser JK, Benhaim P \& Hedrick MH 2002 Human adipose tissue is a source of multipotent stem cells. Molecular Biology of the Cell 13 4279-4295. (doi:10.1091/mbc.E02-02-0105)

Received in final form 21 June 2016

Accepted 22 June 2016

Accepted Preprint published online 23 June 2016 http://joe.endocrinology-journals.org

DOI: 10.1530/JOE-16-0099
๑) 2016 Society for Endocrinology Printed in Great Britain
Published by Bioscientifica Ltd. 